\title{
Interdisciplinary and integrative learning of neuroscience in first-year Psychology students
}

\author{
M.J. Álvarez Comino*, G. González Cuevas*, B. Navarro-Galve**, E. Velarde \\ Fernández** \\ * Department of Psychology, School of Biomedical Sciences and Health, European University of \\ Madrid \\ ** Department of Biomedical Basic Sciences, School Of Biomedical Sciences and Health, European \\ University of Madrid
}

\begin{abstract}
This work describes a novel learning experience designed by professors from four distinct first-year Psychology courses at the European University of Madrid. In general, first-year Psychology students are lacking a sense of interfield integration and unity of neuroscience. Therefore, our ultimate goal was to help students perceive continuity between neuroscience-related courses, promote interprofessionalism, and avoid compartmentalization. The specific aims were to generate transversal knowledge and integrate contents by coordinating and developing interdisciplinary learning activities. These courses share the common thread of teaching the psychological processes: sensation, perception, attention, learning and memory, as well as their biological and neurophysiological bases. This practice was designed to utilize high-impact educational methodologies based on meaningful and experiential learning approaches, in addition to active learning methods such as problem-based learning (PBL). All in all, students improved their knowledge of transversality and interprofessionalism required in learning neuroscience. Introducing these concepts in the training of first-year Psychology students may help in fostering effective strategies in the teaching of psychology.
\end{abstract}

Keywords: interdisciplanarity, neuroscience, experiential learning, transversality, interprofessionalism, psychology

\section{Introduction}

During the academic year of 2013-2014 the undergraduate degree in Psychology (BSc) was inaugurated at the European University of Madrid (EUM). In the beginning weeks we noticed that students showed difficulties in integrating the contents of their interdisciplinary courses, especially in appreciating the complementary value of courses such as Sensation, Perception and Attention, and Learning and Memory (basic psychological processes) and Biology and Physiology (their underlying biological and physiological substrates). For this reason, we set out to create an innovative experience for first-year Psychology students.

Undoubtedly, the field of neuroscience is partly comprised of the above subjects. Therefore, it is important for our students to consider them as forming a cohesive block. The interdisciplinary nature of neuroscience in the context of Health Sciences is a topic that has been introduced into the classroom since the last decade. Indeed, it is of special importance nowadays in Psychology when referring to concentrations, interprofessionalism, and future professional work (Bombín y Caracuel, 2008).

These courses provide knowledge at the forefront of interdisciplinary research, as well as training in skills related to the collection and interpretation of relevant data. In addition, they are also in agreement with the MECES competences (for a review, see Pereira \& Molina, 2012), which include the demonstration of knowledge regarding: (a) the basic laws ruling the various psychological processes; (b) the abnormal and normal processes as well as main stages of psychological development, and (c) the biological underpinnings of human behavior and psychological functions. 
Furthermore, a series of transversal competences are in line with these subjects, such as autonomous learning, information management, capacity to apply practical knowledge, communication and information technology skills, and capacity of analysis and synthesis. The specific competence found in all of the courses is the capacity to describe and measure variables (personality, intelligence and other aptitudes, attitudes, and so on) and cognitive, emotional, psychobiological and behavioral processes.

A common denominator shared by these courses is the inclusion of the psychological processes: sensation, perception, attention, memory, and learning, as well as their underlying biological and neurophysiological substrates. Our priority was to increase the sense of unity of these various subjects by the integration of scientific research methodologies, the application of practical cases through problem-based learning, and basic research knowledge. For this reason, we designed a set of activities meant to contribute to the development of meaningful learning and the above competencies. These activities consisted of visiting the Cerebral Cartography Center and completing an assignment by using material by various courses (a problem-based learning activity with similar structure and orientation) and other specific tasks.

Meaningful learning refers to a way of learning where the new knowledge acquired is related to previous knowledge (Ausubel, 2002; Palmero, 2004). In accordance with this method of learning, this project helped learners connect contents from diverse courses, previous knowledge, and personal experiences. Given that personal experiences played an important role in the learning process, this project also promoted experiential learning (Kolb, 1984).

The main objective was to cover the topics of multidisciplinarity and interprofessionalism in the field of neuroscience. Professors from four different courses taught over three trimesters in the first year of the Psychology degree set out the challenge of generating transversal knowledge and integrating of contents by coordinating and designing of interdisciplinary activities. The specific aims were: (1) to encourage interprofessionalism by sharing a common core that gave students a sense of content continuity; by eliminating content overlapped and compartmentalization; and (2) to create experiencies coordinated by professors belonging to distinct departments and faculties with the ultimate goal of developing projects focused on multidisciplinarity learning.

The concrete actions we implemented to reach the objectives in this project were (a) the design of curricular activities (not only specific for each course but also integrative); (b) the evaluation of such activities; as well as (c) the assessment of the degree of interest and motivation students show.

\section{Methods}

Two groups of students participated in the practice: 19 students from the Psychology degree (all of them taking the four subjects in a transversal manner) and 17 students from the Psychology-Criminology double degree (only taking one of the subjects, Physiology). This second group served as a control to evaluate global results and perception differences among students. 
The subjects that got involved in the experience were: Behavioral biology and Sensation, Perception and Attention (both from the first trimester); Physiology (from the second trimester and the common link between both groups of students); and Learning and Memory processes (from the third trimester).

A variety of formative activities were designed and developed as part of the evaluation system of each subject, including individual tasks, oral presentations, analysis of scientific texts, and tests regarding the contents prepared by the different methodologies (problem-based learning, visit to a Cerebral Cartography Center). The methodologies regarding the present work are summarized below:

Problem Based Learning (PBL) was applied in the four subjects according to a common perspective: introducing the students to the scientific method and neuroscience research, as well as its potential role in diagnosis and clinic application in Psychology (Wood F., 2003). Professionals in neuroscience research from other institutions also participated in specific sessions with the students, in order to tell their experiences and provide information of current neuroscience research. Grades obtained in these PBL assignments were part of the global evaluation plan of the four subjects.

There was an organized visit to the Cerebral Cartography Center, which is dedicated to the study of cerebral function from different experimental approaches including neurophysiology, behavioral tests and microPET neuroimaging (positron emission tomography). This institution is part of the Centers for Research Support coordinated by the Research School of the Complutense University of Madrid, but it is also a Research Entity from the Pluridisciplinar Institute.

All the students were asked to make a reflection prior to the visit to focus their attention on three key points: types of experimental techniques, research projects and their application in Psychology. All answers were divided into two options: yes or no. Sixteen reflections were handed in and their results were analyzed by means of descriptive statistics. After the visit, the students were given an assignment regarding neuroimaging techniques and their role on mental diseases diagnosis. The grade obtained in this task was part of the Physiology evaluation.

Finally, both groups of students filled out a survey requesting their opinion about the transversal activity and the other formative assignments, as well as their perception on connection among subjects. Comparison between both groups of students was used to evaluate the impact of the transversal development of contents. The students from the double degree were used as a control as they only took one of the subjects. Results were organized by means of Likert-type ordinal scales, and data were analyzed by descriptive statistics methods. Mean comparison between groups was estimated by ttest (for independent groups).

\section{Results and Discussion}

Each subject included the grades for the formative activities described above as part of their evaluation plan. 
From the data obtained in the reflection prior to the visit to the Cerebral Cartography Center, it can be inferred that whereas a high percentage of psychology students is aware of the role played by neuroimaging techniques in the study of mental processes such as thinking and emotion (81.3\%), or in lying detection (68.8\%), most of them (93.8 \%) consider that the psychologist's work cannot be replaced by new technologies (Fig 1).

\section{QUESTION 1}

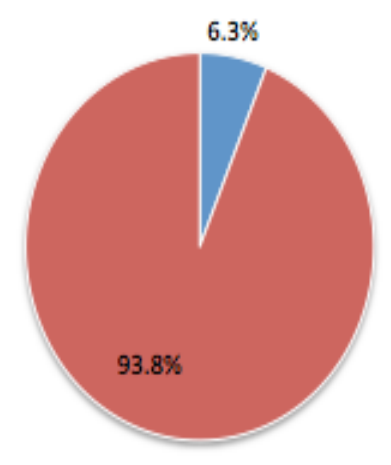

QUESTION 2

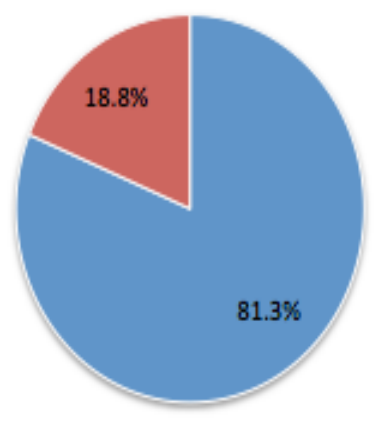

QUESTION 3

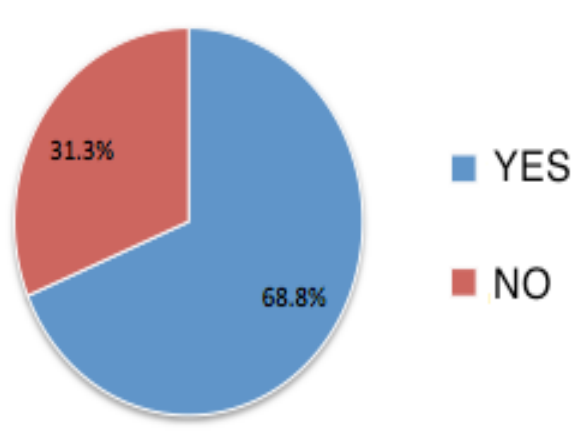

Figure 1. Data obtained from the reflection prior to the visit expressed as percentages to QUESTION 1) Can technological development replace a psychologist work?, QUESTION 2) Can neuroimaging techniques be considered as a way to access thoughts and emotions?, and QUESTION 3) Is it possible to spot a liar?

The results gathered after the visit to the Cerebral Cartography Center show that students from the Psychology group rated it as "quite interesting" (47.1\%) or "very interesting" (52.9\%), meanwhile the double degree students considered it "fairly interesting" (63.6\%) or "quite interesting" (36.4\%) (Fig 2a, Annex). There is a statistically significant difference between each group means: Psychology (4.53 \pm 0.13$)$ vs. Psychology-Criminology (3.36 \pm 0.15$) ; \mathrm{p}<0.001$.

Most of the students from both groups rated the visit at least as "fairly related" to each subject contents. However, the percentage of students that evaluate it as "quite related" or "very related" was higher within the Psychology degree students (100\% in the Psychology group compared with 36,4\% in the Psychology-Criminology group). Among the students of the double degree group, 27.3\% estimated the visit was "slightly related" to class contents. (Fig. 2b, Annex). No statistically significant differences could be found between means of each group: Psychology $(4.00 \pm 0.15)$ vs. Psychology-Criminology (3.55 \pm 0.34$)$; NS.

Regarding a possible collaboration in research projects at the encephalography (EEG) laboratory, $94.1 \%$ of the Psychology group students and $81.8 \%$ of the double degree group showed their interest in taking part (Figure 2c, Annex). We found a statistically significant difference between each group means: Psychology $(3.47 \pm 0.12)$ vs. Psychology-Criminology (2.73 \pm 0.30$) ; \mathrm{p}<0.05$.

Different factors modulated the motivation to participate in a research project in the EEG laboratory, as it can be seen in figure 2d. In the majority of cases (59\% and $62.5 \%$ respectively for each group) the schedule was the main restraint. It is noteworthy that $6.3 \%$ of the Psychology students were willing to participate either way. 
QUESTION 1

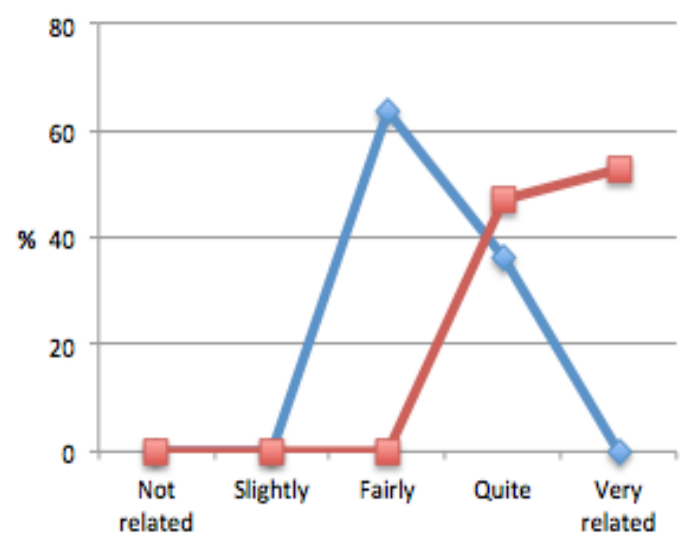

QUESTION 2

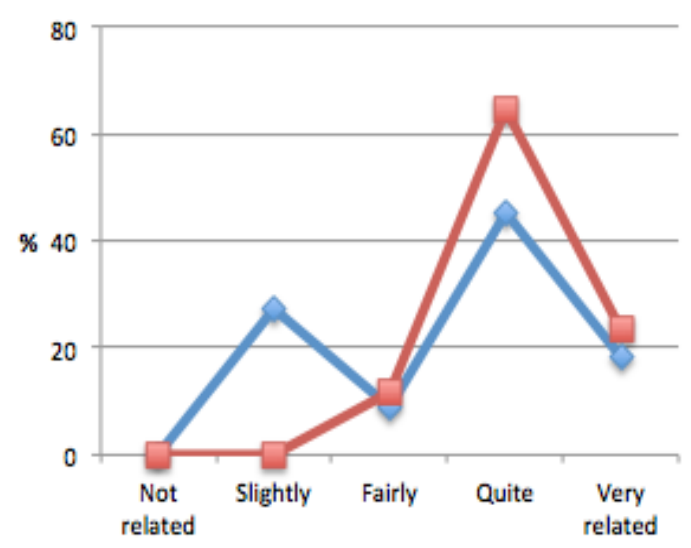

QUESTION 3

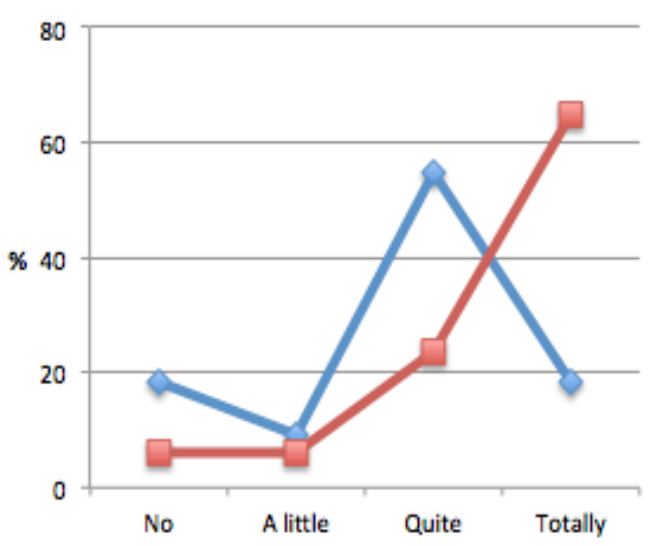

\section{QUESTION 4}

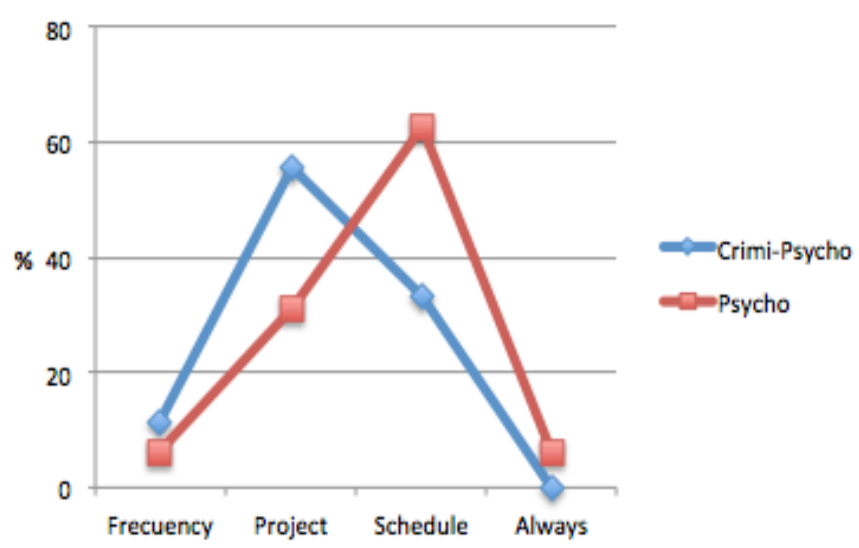

Figure 2. Data obtained from the survey after the visit to the Cerebral Cartography center. a) Evaluate in general terms the visit. b) To what extent do you consider this visit is related to the contents previously seen in class? c) Would you be interested in taking part in some of the research projects developing at the EEG laboratory? d) If so, what would your participation depend on?

These preliminary results suggest that the Psychology group perceived the activity as more interesting, more related to the contents previously studied in class and showed more motivation for taking part in future research programs developed in the center. The reasons for these divergences can be due, in part, to the different subject programming of both groups, as the Psychology-Criminology group did not have some key subjects in the same course as the Psychology group ("Behavioral biology", "Sensation, perception and attention" and "Learning and memory"). Those subjects are fundamental to the correct integration of transversal contents, as well as to the practical application of theoretical knowledge.

In conclusion, coordinated efforts in promoting interdisciplinary and integrative learning of neuroscience in transversal courses increase the satisfaction of students about their learning process, as well as improves the practical implementation of active learning methods. 


\section{Conclusions}

Some of the conclusions that can be inferred from this experience are:

The methodology described in the present work helps to reach an interdisciplinary and transversal teaching approach, which sustains on the fact that most Psychology students found a direct relationship between the proposed transversal activity and the contents explained within each subject. The developed activities allowed the students to be closer to a real research environment, both from a basic and applied perspective, since the very beginning of their higher education, and contributed to spread this kind of learning to other subjects. Moreover, subjects that are normally independently taught were designed in a correlated manner, so that the student can self-integrate the contents. In addition, students were given the valuable opportunity to know the insides of a center for basic and applied research, the Cerebral Cartography Center at the Complutense University of Madrid, which is well-known in the field of neuroimaging. Furthermore, some students were recruited as experimental subjects in research studies of the EEG laboratory at the center, which provided them with firsthand experience in research projects. Last but not least, this practice contributed to improve coordination, not only among departments and schools, but also among professionals, enriching both students and teachers. Professors from two different but complementary neuroscience disciplines (clinical psychologist and neurobiologist) have participated in the present practice coordinating work not only among departments but also schools. Furthermore, professionals from other research institutions and universities have also been involved in the development of the problem-based learning methodology, improving the perceived importance of basic subjects for the student professional future.

The coordination process among teachers of different subjects has contributed to enhance and complement the contents of each subject, to favor the learning process of the students in all subjects as a whole, and to improve student interest and motivation. One of the transversal competences registered in the White Book of the Psychology degree (ANECA, 2005) is "the ability to work in interdisciplinary teams", which is considered by Psychology professionals as one of the most important for future psychologists. Previously described interdisciplinary learning experiences for the Psychology degree reveal some of the benefits of this perspective, such as a more coordinated effort among teachers, better student perception of unity of contents, and a more integrated and less isolated development of subjects.

This novel learning experience can be considered an example of an interdisciplinary and transversal approach on courses for the same degree and academic year.

\section{References}

ANECA (Agencia Nacional de Evaluación de la Calidad y Acreditación). (2005). Libro blanco del título de Grado en Psicología.

http://www.aneca.es/publicaciones/librosblancos.aspxhttp://www.aneca.es/publicaciones/libros-blancos.aspx

Ausubel, D. P. (2002). Adquisición y retención del conocimiento. Una perspectiva cognitiva. Ed. Paidós. Barcelona. 
Bombín, I., \& Caracuel, A. (2008). La especialización en Neuropsicología: desde la necesidad clínica hasta la conveniencia estratégica. Papeles del psicólogo, 29, 291-300.

Gracia, E., García, F., \& Lila, M. (2007). Socialización familiar y ajuste psicosocial: un análisis transversal desde tres disciplinas de la psicología. Valencia: Universitat de València.

Kolb, D. A. (1984): Experiential Learning. Experience as the source of learning and development. Englewood Cliffs, N.J.: Prentice-Hall, Inc.

Insel, T.R. (2010). Circuitos defectuosos. Investigación y Ciencia. 24-31

Ministerio de Educación y Ciencia (2006). Propuesta de directrices para la elaboración de títulos universitarios de Grado y Máster. Secretaría de Estado de Universidades e Investigación: Ministerio de Educación y Ciencia.

Molina, J. G., Rodrigo, M. F., \& Bonavia, T. (2011). La docencia de Estadística en el grado de Psicología: una experiencia de colaboración interdisciplinar con la asignatura de Psicología Social del Trabajo. @tic. revista d'innovació educativa. 6, 21-29.

Moreira, M. A. (2000). Aprendizaje Significativo: teoría y práctica. Ed. Visor. Madrid.

Palmero, M. L. R. (2004). La teoría del aprendizaje significativo. Proceedings of the First International Conference on Concept Mapping, 1, 535-544.

Pereira, C. C., \& Molina, C. M. (2012). La aprobación del marco español de cualificaciones para la educación superior y la empleabilidad del alumnado universitario. REJIE: Revista Jurídica de Investigación e innovación Educativa, (5), 67-86.

Velarde, E., \& Marco, E. M. (2014). Participación interuniversitaria para el diseño y el desarrollo de un ABP. XI Jornadas Internacionales de Innovación Universitaria.

Disponible en:

http://universidadeuropea.es/myfiles/pageposts/jiu/jiiu2014/index.html?_ga=1.26 3099468.1178424653.1382621289

Wood, F. (2003) Problem based learning. Brit Med J. 326:328-330. 